\title{
Proposal for an information system to increase efficiency in the management control of municipal public services
}

\author{
Israel Patiño Galván*, J. Jesús Ceja Pizano \\ Department of Administrative Sciences graduate, Instituto Politécnico Nacional, Mexico DF, México
}

\section{Email address:}

ispa_ga@hotmail.com (I. P. Galván), cejapiza@yahoo.com (J. J. C. Pizano)

\section{To cite this article:}

Israel Patiño Galván, J. Jesús Ceja Pizano. Proposal for an Information System to Increase Efficiency in the Management Control of Municipal Public Services. International Journal of Science, Technology and Society. Vol. 1, No. 3, 2013, pp. 71-83.

doi: $10.11648 /$ j.ijsts.20130103.13

\begin{abstract}
Information systems in the public environment, depend for their successful integration, largely on the needs analysis to make appropriate authorities, as no technology is incorporated as part of the global technology boom, but rather to integrate this as part of an investigation that achieves maximum use of scripts, in order to support the management control of municipally public services, with the help of scientific methodologies, qualitative and quantitative and technological methodologies of intervention to correct structure and foundation of these services. A result of this research is the implementation of a specific information system to improve administrative and operational processes in the attention and follow up of municipality public services. This information was collected in 6 municipalities of Mexico, through field research techniques such as interviews and observation, applied to administrative and operational staff providing this service, in each of the municipalities, while complementing them with 196 applications of citizen surveys.
\end{abstract}

Keywords: Information Systems, Management Control, Municipal Utilities, Citizens

\section{Introduction}

This research is based the need to develop information systems to improve management control of municipal public services and thus meet the needs of population, and in turn, support the municipal authorities. The information systems for management control of municipal utilities, is scarce, hence the problem and identification of the study variables, which are: Structuring a system Information for Control management of municipal public services. It Were the bases for the development of this research proposal.

The municipal government and the services offered depend on the performance of the structure and coordination of each of the areas, in order to perform any and all its functions as are appropriate avoiding having wasted time, resources and especially avoid the chaos between public servants and citizens, of this it is important to give more importance to incorporating technology efficiently to achieve these functions

\section{Methods}

\subsection{Type Scientific Research}

The characteristics of this research to comprise the following types of research: Descriptive, Exploratory, field and propositional. According to Fernandez, Narez \& Garcia (2008) descriptive investigation is the characterization of a fact, phenomenon, individual or group, in order to establish its structure or behavior. Explanatory research is responsible for searching the reason of the facts by establishing cause-effect relationships. In the field research also used, in which the main techniques used were: interview, survey and observation.

The survey according to Hernández Fernández \& Baptista (1997) is a technique for acquiring information of sociological interest, using a questionnaire previously developed. While the structured interview according to Sabino (2002) is characterized by rigidly, identical questions and in the same order to each of the participants, who must choose the answer among two, three or more alternatives that are offered. On the other hand, the non-participant observation according to Hernández et. al (1997) indicates that is the systematic, valid and reliable record of behavior or behavior.

Finally the proactive investigation, According to Del Rincon, Arnal, Latorre \& Sans (1995) suggest that part of a diagnosis, establishing goals and strategies are designed to achieve the objective. 


\subsection{Type of Technological Research}

The type of technological intervention research, according to García (2005), is a finished item, which includes the application of knowledge in specific products that solves a problem, meets a need and facilitates the task, done efficiently or provides comfort.

\subsection{Methodology of Scientific Research}

This investigation was conducted in terms of quality and quantity, according to Rodriguez, Gil \& Garcia (1996) the purpose of qualitative research is to understand and interpret reality, as it is understood by the subjects participating in contexts studied. Briones (2002) states that quantitative research is directly based on the explanatory paradigm, used information quantifiable, with the objetive of try to describe or explain phenomena that studies. Due to the nature of this study the methods following were also used:

1. Analysis and synthesis. According to Fernández et al. (2008), The analysis Theoretical is a procedure by which a complex whole is broken down into its various parts and qualities. While mentally synthesis establishes the link between the parties previously analyzed and allows discover essential relations and general characteristics between them.

2. Systemic functional structure. Its action is evident in the interplay of ideas, connecting concepts, systems coupled with recommendations and strategies it becomes an important avenue for the explanation of the research object.

3. Inductive says Castillo de la Peña (2010), is the reasoning, from the knowledge universal to about knowledge particular.

\subsection{Technological Research Methodology}

Dante says (2006) that technological methodology is a systematic way of performing, managing and administering a project to perform with high chances of success. The methodology, is the lifecycle object-oriented, this allows the code to be reusable.

\section{Theoretical Framework of the Research}

\subsection{International Context of Information Communication Technologies (ICT) in Public Administration}

According to Weissbluth (2008) ICT plays a fundamental role: they are tools that conducive, radical changes in public administration, paradoxically, are the ones that are beyond the comprehension of the reformers who are managing or funding projects public computerization. In this context Gaston \& Naser (2012) should considered that to measure the performance and progress of e-government policies brings with it not only technical aspect, it is also necessary to consider cultural aspect, organizational, political, and social.
Moreover, says Penso (2011) in the case of Mexico, the problems facing is the use of ICT such as: the basic training of employees to operate the technology, the high degree of underutilization of installed capacity, but especially the pressure that falls on employee to be autocapacite.

\subsubsection{Models of Evolution of E-Government}

According to Gaston \& Naser (2012) the United Nations has defined a framework of e-government evolution, according to four levels of maturity, which served as a reference for countries to define their own models:

a) Emergent level: The country is committed to develop e-government, offers information on a single way (government to citizen).

b) Improved level: It communication wide from one to two-way with the public, through email, downloadable forms, applications, audio, video and filing.

c) Transactional Level: The State offers complete and secure transactions such as payment of taxes and fines, registrations, obtaining permits, licenses and certificates among others.

d) Connected Level: The Information, data and knowledge are transferred between organisms, for instant access to state services in an integrated manner and with a citizen-centered approach, where e-services are organized around events, and segmented groups.

\subsubsection{Process of Incorporating ICT}

The process of incorporating ICT, according to Montaño (2008) is as follows:

1. Preparing the environment.

2. Awareness of Innovation.

3. Exploring Technology Resources.

4. Exploring Educational Resources.

5. Generating proposals or prototypes.

6. Feedback.

\subsubsection{Benefit of E-Government}

According to Garson (2003), a understanding these benefits, is as results of certain actions and e-government initiatives. In this sense the contributions can be summarized as follows: improving the quality of public services, efficiency and productivity in government processes and operations, transparency and accountability, citizen participation, regulatory framework to support e-government.

\subsubsection{Trends in E-Government}

According to Gaston \& Naser (2012), the trends on the issues that are currently being developed with more force in developed countries and probably will develop in Latin America in the short term, with the advantage of incorporating lessons and adaptations, to learn from these such as.
$>$ Disaster Recovery
$>$ Cloud computing
$>$ citizen Participation
$>$ E-government indicators 
open Government

\subsection{Background of Municipal Utilities in Mexico}

In Mexico, it was until 1917 when the municipal management will appear, in this, the municipalities are regulated under the provisions of Article 115 of the General Constitution of the Mexican Republic. In section III of this article, it is noted that the municipalities with the assistance of the States, will be responsible for the following public services:

1. Drinking Water, Sewerage, Drainage and Wastewater

2. Street lighting

3. Clean and waste disposal

4. Markets and supply centers

5. Pantheons

6. Trail

7. Streets, parks, gardens and recreation

8. Public safety and traffic

9. Beautification and conservation of the villages, cities and works of social interest

10. Social assistance in the area of competence,

11. Employment.

\subsubsection{Classification of the Municipality Public Services} (MPS)

According to Serra (2002), public services can be classified into four categories:

1. International public services.

2. Federal public services.

3. Public services of the states.

4. Municipally public services

\subsection{Context of Information Systems}

Information systems, according to Andreu \& Valor (1991) are a formal set of processes that operate on a collection of data structured, according to the needs of the company. They are responsible to collect process and distribute information selectively required for the operation of the company.

\subsubsection{Classification of Information Systems (IS)}

According to Edwards, Ward \& Bythesway (1998) and Garcia (2000) information systems are classified as follows:

1. Degree of formality

2. automation

3. Relationship with the decision take

4. functionality

5. degree Specialization

Laundon \& Laudon (1996), established the following classification of information systems:

1. Operations Processing System

2. Knowledge Work Systems

3. Automation systems in the Office

4. Information Management Systems

5. Systems for Decision Support

6. Management Support Systems

\section{Results}

The proposed information system is an alternative to improve efficiency in the management control of municipal public services, including therein the administrative and operational processes involved in attention, monitoring and completion of Municipal public service (MPS). It is suggested that this proposal is composed of four phases, each 2 months.

The first phase includes the planning, analysis, design, specification and implementation of the information system. After the first phase, it will be able to operate the system. In the second phase will begin with the validation of this. In the third phase,

The Maintenance of the information system, evaluation and collection of information concerning the operation of the system as well as administrative and operational procedures involved in this. In the fourth and final phase, is incorporated the review stage. Will be reviewed each module in isolation. The development of this proposal depends heavily on coordination and work plan agreed between the authorities and among stakeholders and respect of dates proposed in this research, same that are based on collection and analysis of information, coupled with the experience you have on technological development.

\subsection{Objective Information System}

Conduct a detailed analysis, to implement an information system and this will serve to improve the control of management of MPS, and project this to the short, medium and long term. In addition to selecting development tools, security levels required for the protection of information and the use case diagrams that exemplified to detail the scope and overall system.

Also looking for the best way, that the information system be easy to implement and use, and encourage their feedback and interaction among the actors involved in the process of management control of such municipally public services.

In Figure 1, is presented the proposal with the aspects that comprise.

\subsection{Viability Analysis}

The viability analysis that described below, suggests that the information system either an alternative to improve management control of municipal utilities, covering the following points.

\subsubsection{Technical Viability}

It envisages the creation of an information system, whose features gradually support, the current administrative and operational activities, such as customization by address municipal utilities and various areas that comprise. These features are intended to increase efficiency in the management control of municipal utilities, in addition to contemplate, the interaction of municipal authorities and citizens. 


\subsubsection{Technology Available to Meet the Needs}

It has the technology (hardware - software) available to meet the needs of users, the advantage you have is, first implementation of this model will gradually, and secondly, it has the minimum technological requirements for implementation.

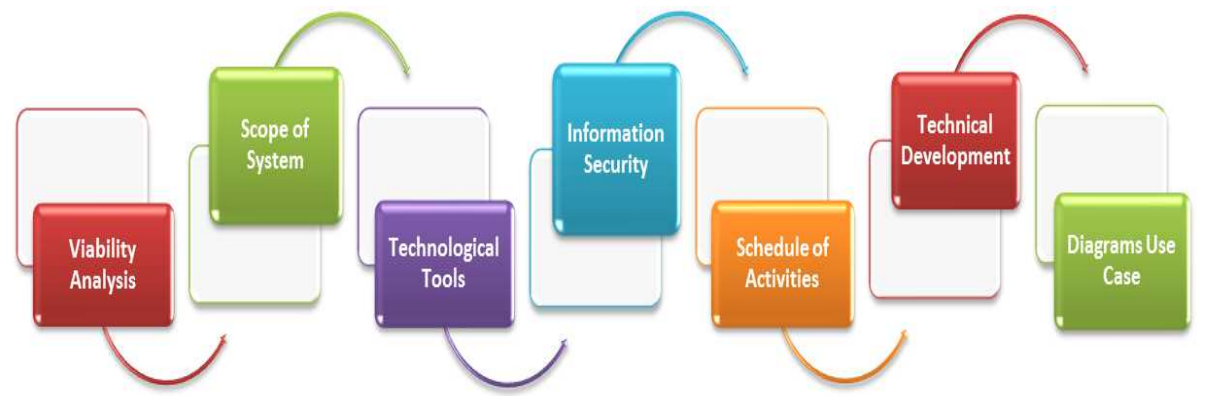

Figure 1. Aspects that make up the information system

In relation to the technological requirements, already has the infrastructure for the implementation of this model, the Government of Mexico, through the Directorate General of the State Information System (DGSIS) provides support to the municipalities of the State of Mexico for the development of portals / websites that they request.

In this technology exist two infrastructures, first infrastructure robust is where the data, information consultation, and traffic applications (server) and second the light part (client), which is from where you will be making the requests, in addition to sending the information to the infrastructure Robust.

Regarding the customer infrastructure, the municipal authorities (by collecting information) already have the infrastructure and the server, provided by the DGSIS.

Table 1. Minimum Hardware and Software Requirements

\begin{tabular}{|c|c|}
\hline \multicolumn{2}{|c|}{ Minimum Requirements } \\
\hline Hardware & Software \\
\hline Pentium III or higher, minimum: 1,0 & Windows XP SP3 / Windows Vista \\
\hline $\mathrm{GHz}$ & SP2 / Windows SP1 \\
\hline RAM Memory: Minimum 256 KB & $\begin{array}{l}\text { SQL } 2008 \text { Standard / SQL } 2012 \\
\text { Standard }\end{array}$ \\
\hline $\begin{array}{l}\text { Hard drive: } 1 \text { GB minimum } \\
\text { available }\end{array}$ & NET Framework 4.0 \\
\hline Unit CD / DVD & Silverlight 4.0 \\
\hline Network Card & $\begin{array}{l}\text { Internet Explorer ver. } 8.0 \text { o top. } \\
\text { Firefox } 14.0 \text { o top }\end{array}$ \\
\hline Video card Minimum: $16 \mathrm{MB}$ & \\
\hline Monitor & \\
\hline Keyboard & \\
\hline Mouse & \\
\hline
\end{tabular}

The requirements minimum of hardware and software is presented in Table 1. Derived from the specifications of server computers is recommended annually expand space storage (Hard Drive), approximately between 17.30 and 19.10 GB, calculation database derivative. Note that this proposal is an approximate average, with a margin of error of plus - minus $5 \%$. If the increase of the proposed hard drive, adding that it will be a backup and compression of last year, considering a compression factor of $40 \%$, since they are mostly data of type text and image in PDF / JPG.

The increase of the hard disk is required annually will approximately between 10.40 and 11.50 GB per year.

\subsubsection{Economic Viability}

1. Time of systems analysts. An estimated 2 months between each release phase as the analysis, planning, development, testing and implementation, with the goal of completing the activities in the planned time.

2. Economic cost of systems. Given that this proposal seeks to leverage existing resources, and that a preliminary analysis of the requirements, the economic cost to the municipality is void, considering the resources of the Directorate General of the State System of Computer.

3. Time that employees will be dedicated to learn of system. In relation to the study conducted with the administrative and operational staff, taken in the sample, will be made by appointment with management to assign corresponding dates to affect the minimum possible time.

4. Estimated economic cost of hardware. The hardware cost will be absorbed by the support offered by the Directorate General of the State System of Computing, because it has the infrastructure to service municipal requirements, and also has the minimum requirements necessary for the implementation of the information system.

5. Economic cost of commercial software or software development. The development of the system will be borne by the Directorate General of the State System of Computing, so this cost is covered. Regarding the economic cost of software, given that existing tools will be used, this will also be null for the municipality of Ecatepec.

\subsubsection{Operational Viability}

At this stage you must ensure its use, consider all possible adverse scenarios, in order to prevent and suggest alternative solutions.

a. If the system will work when installed. To ensure that the system will work when installed, it is recommended to test on other computers, in a development environment - evidence, and in a production environment for its operation, and ultimately be used by the corresponding areas, after training. 
b. The system will be used. Since it is a new system, and comes from an academic research project in which you want to know the results of the objectives pursued, is projected, by the respective analysis, that the information system can be operated the end of its first phase. Thereby ensuring its use by the municipal authorities and later to citizens.

\subsection{Technology Tools}

For the development of the information system, regardless of the technological tools that are proposed herein should not be a major factor for proper development, implementation and system functionality.

Since the needs analysis, design and planning is the core of the system. It is can select any tool to implement the solution technologically.

In phase one of the information system, is where you will carry out the system design at this stage of development, are generated the diagrams for understanding the requirements and also process flows for the operation of municipal public services.

Presented below, some tools proposals for technological development of the information system among these are the tools available to the Directorate General of the State System of Information of the Government of the State of Mexico.

\subsubsection{Modeling $U M L$}

- Enterprise Architect 2.4.1.

- Star UML.

- Microsoft Visio 2010

\subsubsection{Modeling Data Base}

- Erwin Data Modeler 7.3.

- Microsoft Visio 2010.

\subsubsection{Application Layer}

- Java.

- Visual Studio 2012

\subsubsection{Layer of Data Base}

- $\quad$ Oracle $11 \mathrm{~g}$.

- SQL server 2012.

\subsection{Information Security}

This section is important to base regulatory and operational use of the services and mechanisms of the information security.

In the normative par, According to the Federal Law on Protection of Personal Data held by individuals (2012), Chapter I, Article III, Section VI, indicates that the information sensitive personal data such: Personal data which affect the most intimate of the proprietor, or whose misuse can lead to discrimination or involves a serious risk.

In particular, are considered sensitive under that law, those aspects that may reveal racial or ethnic origin, health status, present and future, genetic information, religious, philosophical and moral beliefs, union membership, political views, sexual preference.
Moreover, according to Daltabuit, Hernandez, Mallen \& Vázquez (2007), when referring to information are talking about information management, which ranges from your computer, systematization, creation, storage and transmission.

These processes of information security appear together with our species and to some extent characterized. They are above processes to the appearance of computing.

Though, since the middle of this century have undergone a radical transformation, due to the invention and widespread use of computers

The information can be in four states:

a) Acquisition

b) Creation

c) Storage

d) Transmission

And in each of these states has four security properties:

a) Confidence

b) Integrity

c) Authenticity

d) Availability

For the feedback be constructive, the information should be safe. Services and security mechanisms (ISO 7498 - 2) page are the following, according to Table 2.

Table 2. Services and security mechanisms.

\begin{tabular}{ll}
\hline Services & Mechanisms \\
\hline Confidence & $\begin{array}{l}\text { Encryption (Symmetric and } \\
\text { asymmetric) }\end{array}$ \\
Integrity Check & Hash, Symmetric Encryption \\
Authentication & $\begin{array}{l}\text { Digital signature, hash, encryption } \\
\text { (Symmetric and Asymmetric) }\end{array}$ \\
Non-repudiation & Digital signature \\
Access Control & Access Control Models \\
\hline
\end{tabular}

Source: Daltabuit, Hernández, Mallen, \& Vázquez (2007), the information security

In the case of this proposal, it is recommended protecting of the information following:

Information to protect:

- System User.

- Password.

- Name of the citizen.

- Street.

- Colony.

- Phone.

- Gender.

Proposal for cryptographic protocol:

A. Objective. Confidentiality / Integrity

B. Assumption.

- $\quad$ Each user will keep your private key.

- It is responsibility to the user not compromise the private key.

- $\quad$ Public and private keys are generated by a regulator. In this case it is proposed to generate the Directorate General of the State System of Computing.

- It is suggested that the delivery of private keys is physically by administrator system. 
C. Proposed algorithms

- $\quad$ Asymmetric: RSA

- Functions Hash; SHA - 1/ SHA - 2

D. Security Mechanism to implement in the information system

- Confidentiality: Asymmetric Encryption.

- Authentication: Hash Functions

- Access control: Multilevel Bell-La Padula / Based in roles

Below equations security services to implement, for purposes of the equation will be with data to protect (example), assuming it is the same procedure for the others data.

E. Generates posts:

- Ma1. System User.

- Mp. Password.

- Mn. Name of the citizen.

- Mca. Street.

- Mco. Colony.

- Mt. phone.

- Mg. Gender

Sequence of equations for implementing confidentiality and authentication:

A: Generates posts Ma1.

1. $\mathrm{A}: \mathrm{EK}_{\mathrm{b}}{ }^{\mathrm{pub}}(\mathrm{Ma} 1)=\mathrm{CMa} 1$

2. $\mathrm{A}: \mathrm{H}(\mathrm{Ma} 1)=\mathrm{VMa} 1$

3. A: A $\rightarrow$ B: CMa1, VMal

4. $\mathrm{B}: \mathrm{DK}_{\mathrm{b}}{ }^{\text {priv }}(\mathrm{CMa} 1)=\mathrm{Ma} 1$

5. $\mathrm{B}: \mathrm{H}(\mathrm{Ma} 1)=\mathrm{VMa} 2$

6. B: Si VMa2 = VMa1, ensures integrity

Furthermore, is presented the Figure 2 to purposes of explaining the equations.

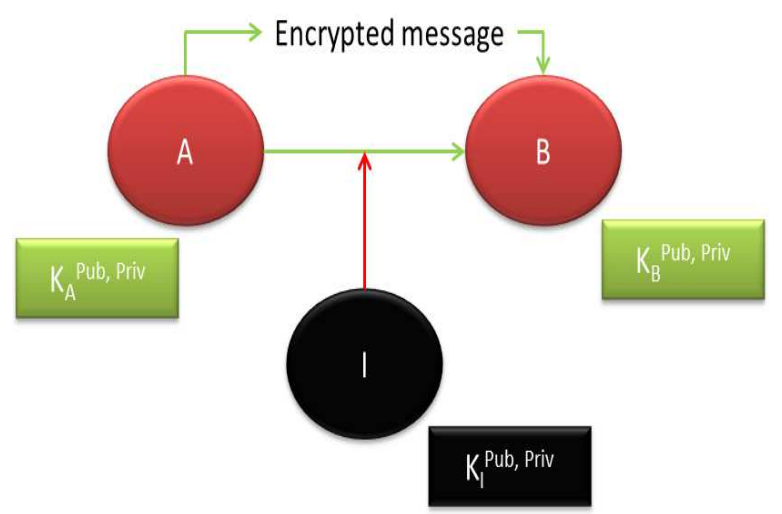

Figure 2. Diagram of the security services

Explanation of the diagram and equation

1. Entity A generates the message "UsrAdmin"

2. Entity A by Asymmetric RSA algorithm, encrypts the message "UserAdmin" with the public key of entity B, resulting in an encrypted message, for example: "\$3\$\% $\%$ TfGn" = CMa1

3. Entity A, generating the hash of the message "User Admin" with the SHA1 function, resulting in a hash, eg “\%4\#4\$\%tgF32" = VMa1
4. Entity A sends messages CMa1 y VMa1.

5. The entity B by the asymmetric algorithm RSA, decrypted the message "\$ $3 \$ \% \&$ TfGn" with the private key of entity $\mathrm{B}$, resulting in a decrypted, for example: "\$3\$\% UsrAdmin" = Ma1

6. The entity B, generates the hash of the message "User Admin" with the SHA1 function, resulting in a hash, eg "\%4\#4\$tgF32" = VMa2

7. Finally entity B, compare results VMa2 VMA1, if equal means that the integrity is guaranteed.

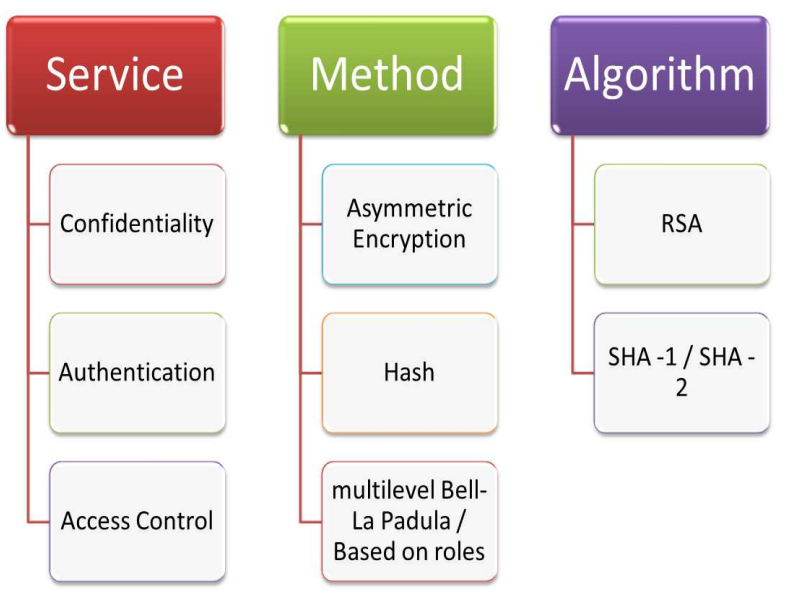

Figure 3. Diagram of services and security methods

On the other hand, it is recommended to implement fingerprint later to avoid decryption attacks, according to the type of service required, and include where necessary, other security mechanisms.

To implement access control model is recommended the model Bell - Lapadula that was developed by D.E. Bell and L.J. Pendula in 1976. This model formalizes multilevel security policy, and is that classifies information into four levels: not classified, confidential, secret and top secret. The information is described in terms of compartments.

This is a policy, that people can have access to information that is to its authorized level, with the aim of controlling the flow of information; this model also helps in building security systems that can be verified.

This service aims to generate 4 roles to control access to the system, which would be the following:

1. The first is an admin role. This can take access all the system and perform all operations allowed.

2. The second role is a role operation, for each direction of municipal public services

3. The third role is that of the user. Where you can only access options necessary to apply and monitor the application of SPM

4. The third role is consultation. Where there may be an operation, you can only view information

It is proposed that the system allows the creation of different roles, which will have a specific goal.

Presented below are the services and methods of information security that is recommended to implement the proposal, according to Figure 3. 


\subsection{Development Techniques}

Given the nature of the research, we recommend using the technological development methodology called Object Oriented and within it, the cycle of life object-oriented.

The reason for the choice of this methodology is that you should create many blocks to develop the system, which will be linked between them (feedback), with the aim of reviewing blocks each section and functionality separately, such as permitted by this methodology.

Also, meanwhile the application procedures, monitoring and care of municipal public services are mostly similar, it is recommended to develop a modular way, if any other service is integrated not due to make a development additional, and configure the system to recognize the addition of the new process, respecting the corresponding administrative and operational procedures.

Furthermore, since the application procedures, monitoring and care of municipal public services are mostly similar, it is recommended to develop a modular way, if any other service is integrated, not due to make a development additional, and configure the system to recognize the addition of the new process, respecting the corresponding administrative and operational procedures.
That is, while more detail is the need and it is clear, will be less likely to do Extemporaneous corrections in the system.

\subsection{Diagrams of the Information System}

This section show of way generally the main need to cover the information system, and derivative thereof, is necessary to agree among development actors (local authorities and DGSIS), detailed explanation of the models, to answer questions or doubts and eliminate the responsibilities of each.

Due to the above, various proposals of diagrams are presented, as are the use case diagram (belonging to the UML diagrams), diagram relational database, the star database diagram, for data mining, among other.

\subsubsection{The Use Case Diagram}

For purposes of this proposal, are presented in general terms the use case diagram that illustrates comprehensively the procedure for applying, monitoring and treatment of municipal public services.

Derived from this point and field research, is created the model of database for system development. In Figure 4, the general use case of municipal public services presented below.

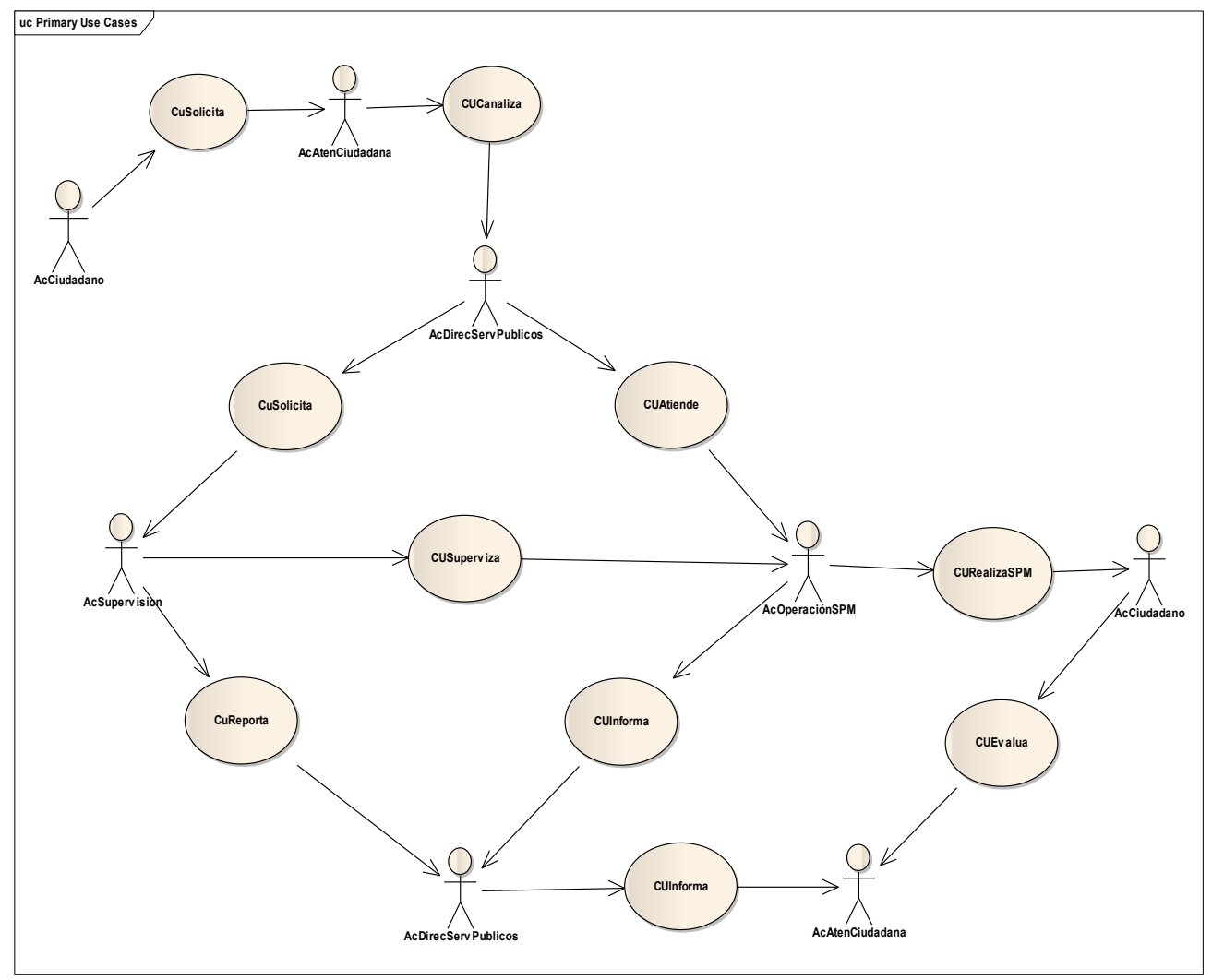

Figure 4. Diagram of general use case of municipal public services

It should be noted, that this is a proposed use cases general diagram for the application, monitoring and care of municipal public service. According to the needs and future projections can be proposed diagrams specific use cases, derived from each use case presented, as required.

\section{Explanation of the use case diagram}

1. The citizen requests a Municipal Public Service (MPS)

2. The address retrieves and analyzes the request for citizen, about to the municipality public service. 
3. Once the request is taking for the direction of municipal public services, it performs the following:

a. The user requests to supervisor make the monitoring for the operating area of the municipality public service

b. He asks the operational area of MPS, attend the municipal public service request

4. The area of operation of MPS runs public service requested by the citizen.

5. The area of operation of SPM informs the leadership the details of the service requested.

6. The monitoring area, report the details of the requested service to the direction of municipal public services.

7. The leadership, reports detail the service requested by the citizen.

8. The citizen evaluates the service received, and informs the citizen service area and save the report.

Actors

1. AcCiudadano. Citizen

2. AcAtenCiudadana. Management / Area for citizen

3. AcDirecServPublicos. management of municipal public service

4. AcSupervision. Supervision Area.

5. AcOperaciónSPM. Area of Operation of Municipal Public Service.

Use case.

1. CUSolicita. Request

2. CUCanaliza. Channeled

3. CUAtiende. Attend

4. CUSuperviza. Monitors

5. CUReporta. Report
6. CUInforma. Informa

7. CUEjecutaSPM. Doing of Municipal Public Service

8. CUEvalua. Evaluates the service received

\subsubsection{Diagram Relational Database}

Moreover and not least important, is model of database relational, which is derived from the research and analysis of information from existing administrative and operational procedures.

In particular, the three operators (structural appearance, appearance of integrity, appearance of handling) of the data base are important: restrict, project and join (the latter operator is also known as combine or assembly).

Based on these operations are presented below, the general statement derived from the natural process of the application, monitoring and care of public services, and relational database diagram: The citizen requests a Municipal Public Services (MPS) from the attention citizen service, which receives and channels the request to the municipal utilities. After taking the request the direction municipal utilities doing the next:

1. Requests the service monitoring to be carried out by the operational area of MPS. It asks the operational area of MPS attend municipal public service. Subsequently, the area of operation of SPM makes the requested for the citizen. In turn informs the direction of municipal public service.

Once done, the area of supervision reports the details of the requested service to the direction of public services. Finally, the citizen evaluates the service you received and informs the citizen service area to save the report.

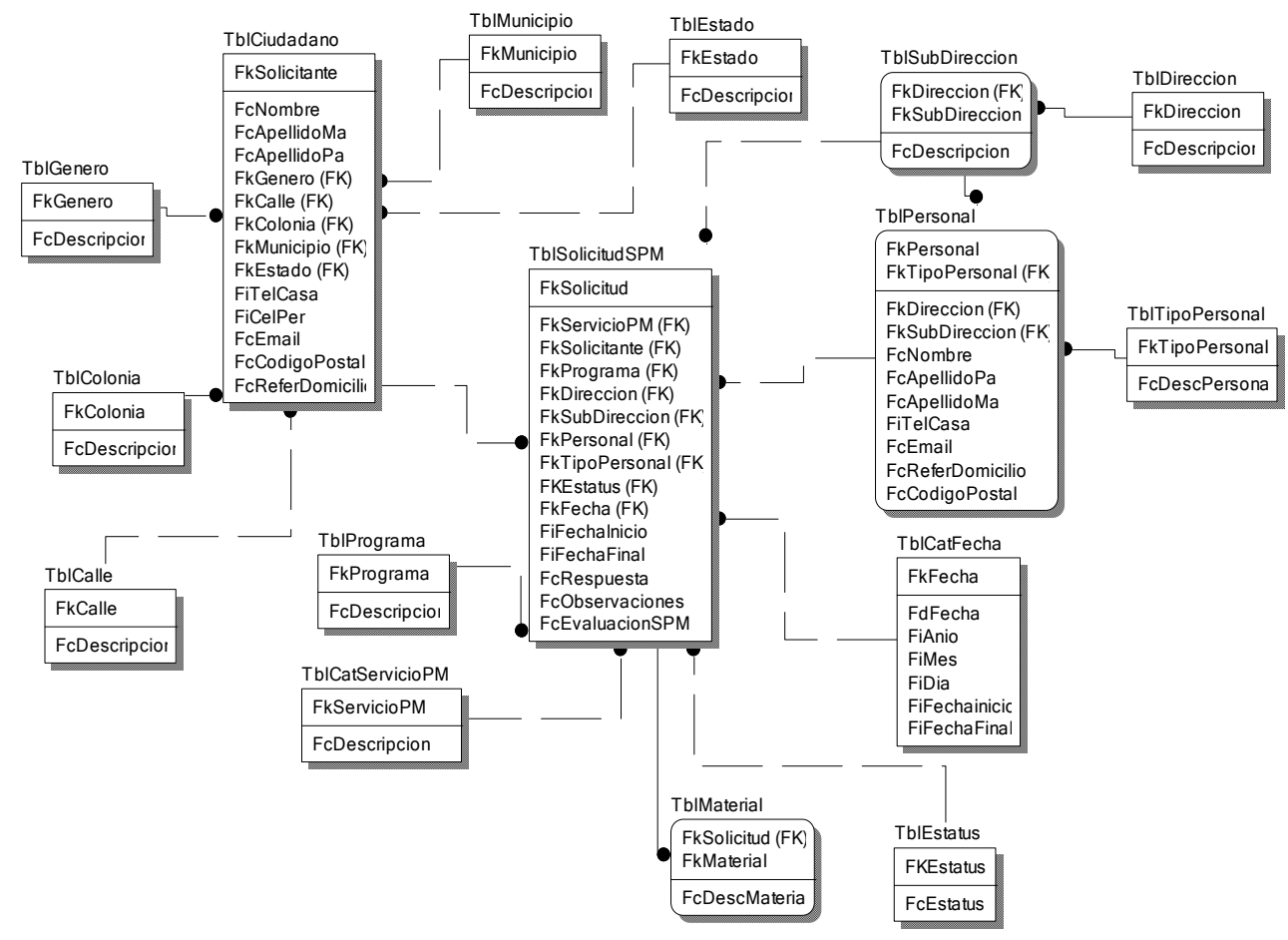

Figure 5. Model entity - relationship 


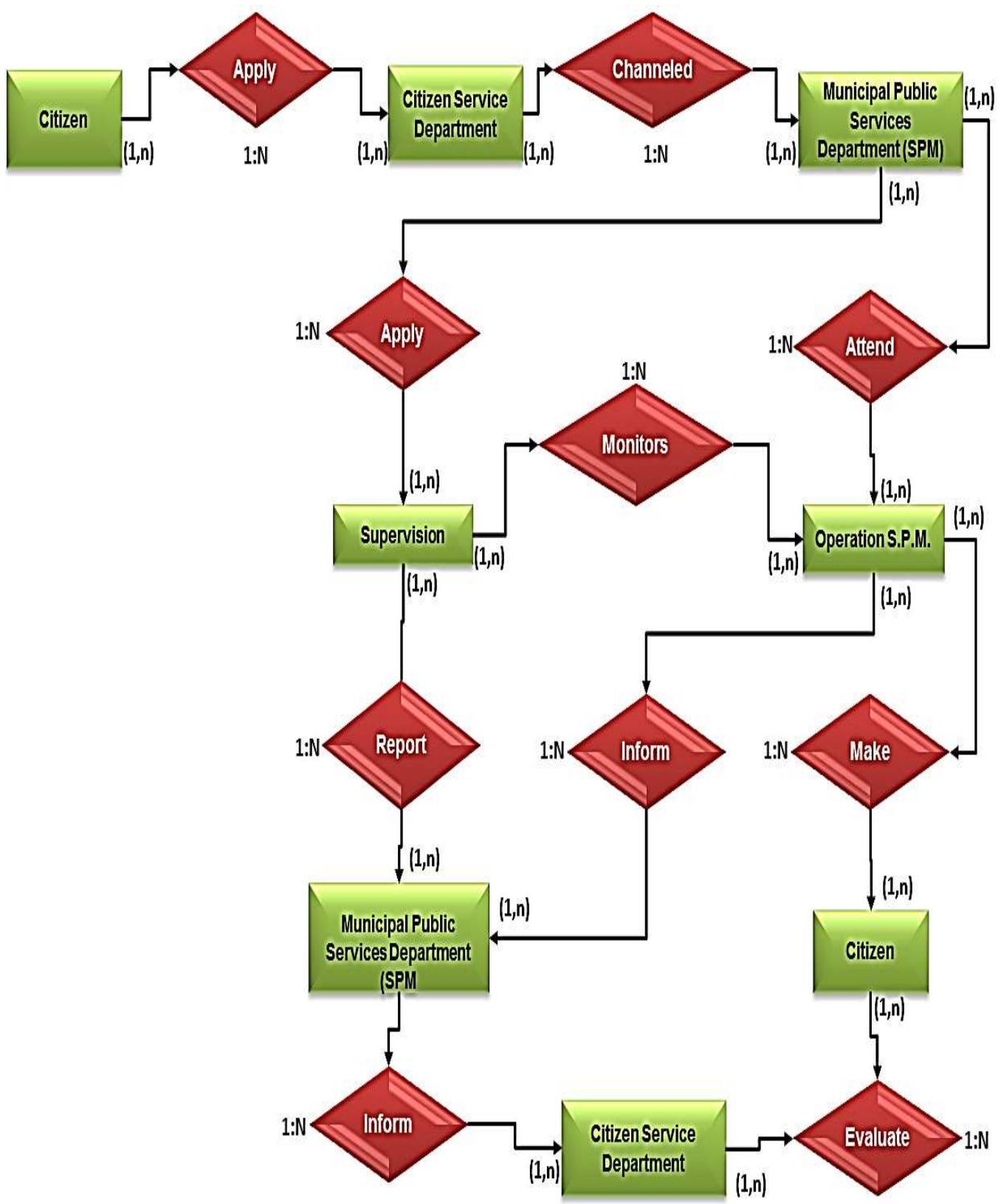

Figure 6. Relational model

Derivative of the earlier statement, the proposed model of database of entity - below - relationship, is presented the Figure 5. As well as the relational model, according to Figure 6

\subsubsection{Database of Star Diagram for Data Mining}

The following steps are proposed for the star diagram:

1. As of formal definition has both research was conducted as the detailed diagrams of the information system, including the statement of requirement, generally.

2. Doing the Mapping entity relationship model, it is made the diagrams of databases included in the project

3. Model relational database is included, based on the field research and modeling in the relational.

4. and 5. The Development Suggested of reporting applications, depending on the needs. This draft will be performing an application, derived from the use case diagrams and database a star diagram for generating data cubes.

6. The implementation of this procedure at the end of system development is recommended, according to the implementation schedule.

7. Maintenance and growth. It is recommended to include in the maintenance of the information system.

8. Regarding project management, it is important to determine the extent of this type of approach with respect to the need, and that is not only implementing tools for its boom or fashion but because they really require, and also define that part these tools will be useful for the main goal they pursued.

Presented below in Figure 7, the star diagram to create the cube to starting relational data diagram 


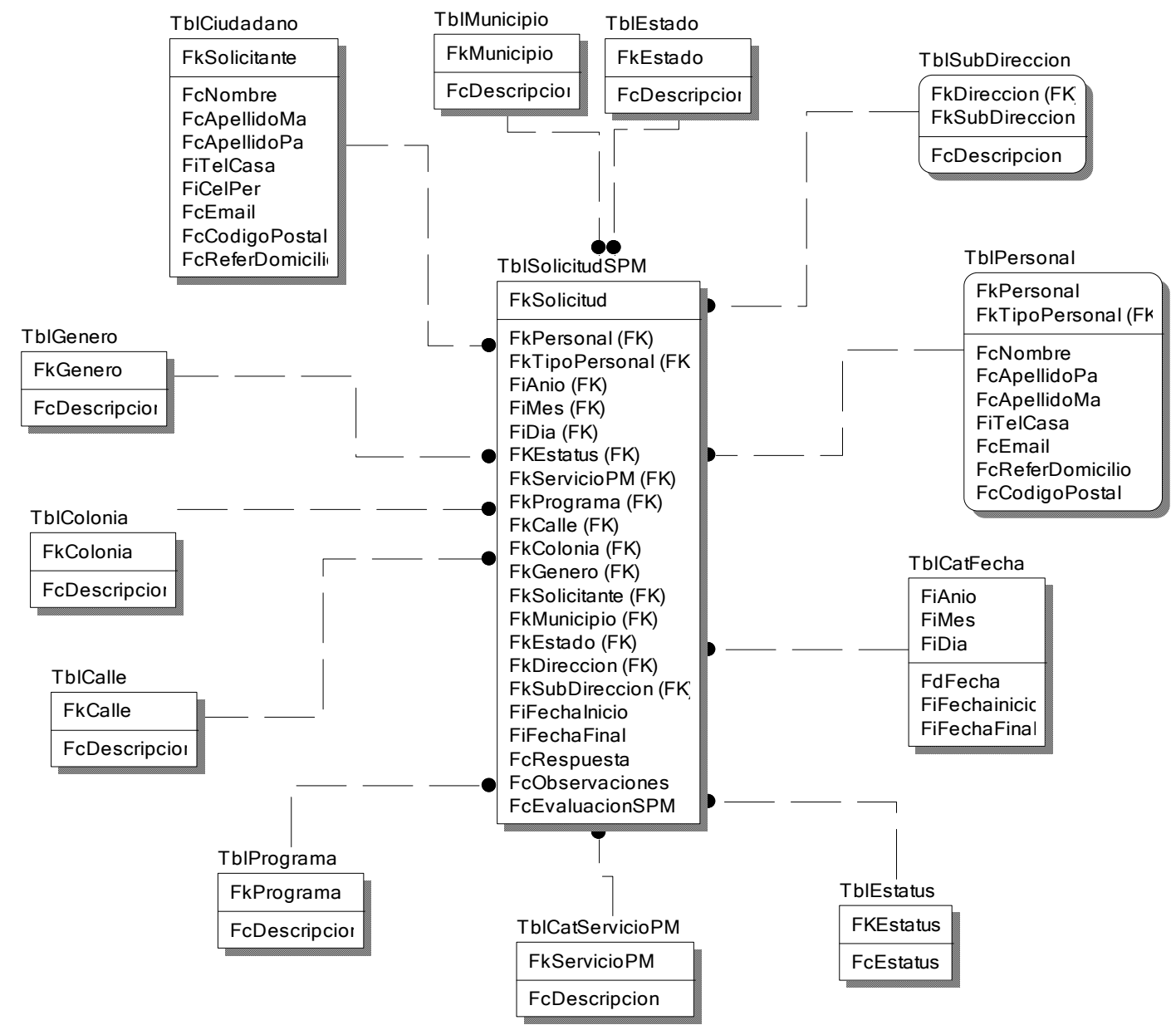

Figure 7. Star diagram

Note that this model and feed tables of information that tables fill the relational model, as this star design databases are unstandardized to create the dimension tables.

\section{A. Fact Table}

\section{TblSolicitudSPM}

B. Table of dimensions.

TblCalle, TblCatFecha, TblCatServicioPM, TblCiudadano, TblColonia, TblEstado, TblEstatus, TblGénero, TblMunicipio, TblPersonal, TblPrograma, TblSubDirección

Note that this is a general diagram star, depending on the needs and future projections it is can propose more models and designs as required.

\subsubsection{Information System Diagram}

Respecting the wording that was used in the above diagrams, the flow in the application of a municipal utility, the use of the information system is explained as follows.

\section{Request for an SPM}

1. The citizen requests a municipal public service (MPS):

a. May be requested by the information system - IS (through a catalog MPS) from internet, anywhere you have access to it. It is recommended that the municipal authorities through outreach programs, coverage and scope, can bring the technology to citizens and they can request from said means. You must enter the necessary data so that it can provide the service, such as address, telephone number and name, among others.

b. Another channel request is going to the Direction of Citizen Attention of the Municipal Public Service (DCAMPS), to request the service, whether they would provide a computer with internet access or staff of Citizen Services supports them to enter the application.

2. Once it is entered the application, the information system given a folio number and a user ID, which is provided to the public, that through this page and user tracking application is given anywhere in the flow process, as well as contact details, so that citizens can know what is the reason for any delay or simply know the status of your application.

3. The DCAMPS transfers the request to the municipal public service.

a. Once the request is entered to IS, the DCAMPS oversees the application has been forwarded automatically to the address provided by the 
municipal utility and verify that the direction will service accepts the request.

b. If more than 48 hours exceeds the acceptance of the application, the DCAMPS will follow up with the appropriate direction to know what is the reason for the delay, and to lay this on the SI.

4. After the request, taking the direction of municipal utilities, it performs the following:

a. It asks the operational area of the application of SPM attend municipal public service.

b. It enters at system, service to be held, the date and time on the same attempt.

c. The system will have the ability to receive scanned offices in JPG and / or PDF format, such as notes or bills; they should be required, in order to justify the expense to be held.

d. In case of any delay in care folio introduced that direction the reason for the delay, as well as the reallocation of the date and time that the service fee.

e. In turn, this direction sought by the system, the intervention of area supervision, to monitoring the service to be carried out by the operational area of MPS is performed

5. The area of operation of MPS takes the public services that citizens requested.

a. Once the area of operation of the service receives the request through the foil, accept service

b. In addition to confirming the resources the service will be used.

c. After the area of operation of MPS accepts the service, and thus the date and time it was made, the user is notified for email and by status in the IS, the service shall be made on the date and time indicated.

6. The area of operation of MPS reports to direction of municipal public service details that are requested.

a. Once the service with the relevant page number is complete, that area enters the IS, detailed service, such as arrival time end time, anomalies and other relevant details of the service.

b. It also need to introduce in the IS, a status that indicates that the service has been served.

c. Giving by attended the service, notifies MPS to Directorate and the DCAMPS. By email and status within the information system.

7. The monitoring area reported the details of the requested service to the direction of public services.

a. Once the service number for the folio is finished, this area introduced into the IS, detailed service, such as arrival time, end time, anomalies and other relevant details of the service.

b. Giving by attended the service, notifies MPS directorate and the DCAMPS, via email and status within the information system.

8. The direction of public service reports detail the service requested by the citizen a. Once this address is notified of service attended by the operational area, you must enter the system and see the details of the service and enter their observations of the same, considering the information of the operational area and area monitoring.

b. After entering comments, you must to terminate in the IS, the service.

c. When the service from this direction is terminated is notified via email and through the SI, the DCAMPS.

9. The DCAMPS receives notification of completion.

a. Once that direction receives the completion notification by the Directorate of MPS, analyzes the information provided by those who were involved in the care of the service, as well as enter comments on it, in order to improve service.

b. Finally assign the status of the service completed in the IS. Once you assign this status to citizens and notified via email by IS., The service has been completed.

c. Note that the service sheet does not close until now flow.

10. The citizen evaluates the service you received and informs the citizen service area and report to save the report.

a. After the citizen receives the notification, checks detailed service directions intervened and enters the observations and comments on the same system, in order to offer better or anomalies in service delivery.

b. Should be to terminate the service at the IS finally. So far Folio close completely. In this section within 5 calendar days shall be given to close the service. If the city cannot close it, the area is empowered to close DCAMPS, once the term ended. Same as IS and notified by email by the system.

c. Once Folio closed by the user is sent to all involved in the care of the sheet, through emails and notifications through the reporting IS the end of service.

d. Importantly, it is recommended that the user closes the service to conclude the attention of the relevant page.

\section{Annulment}

If it is required to cancel the service, it should be completed only by the DCAMPS. If not specified in the system the reason for cancellation it is noteworthy that the area requesting the cancellation shall introduce in the IS, the reason for cancellation.

\section{Request of a New Service}

In case you need a new municipal public service, for an existing user must only enter your user name and confirm their data since the first time I applied for a SPM, data is stored in the IS. If you require any changes in personal data, you must enter them into the information system. 


\section{Check Status of MPS}

For the query the status of all request, may be made in the system by the folio number (which is unique), and in the case of the citizen must also enter your user ID in the IS.
Using a flow chart that will be online in this IS, you can visualize where in the flow the request and is also responsible area, along with information on the same, in order that the DCAMPS and citizens can follow the service.

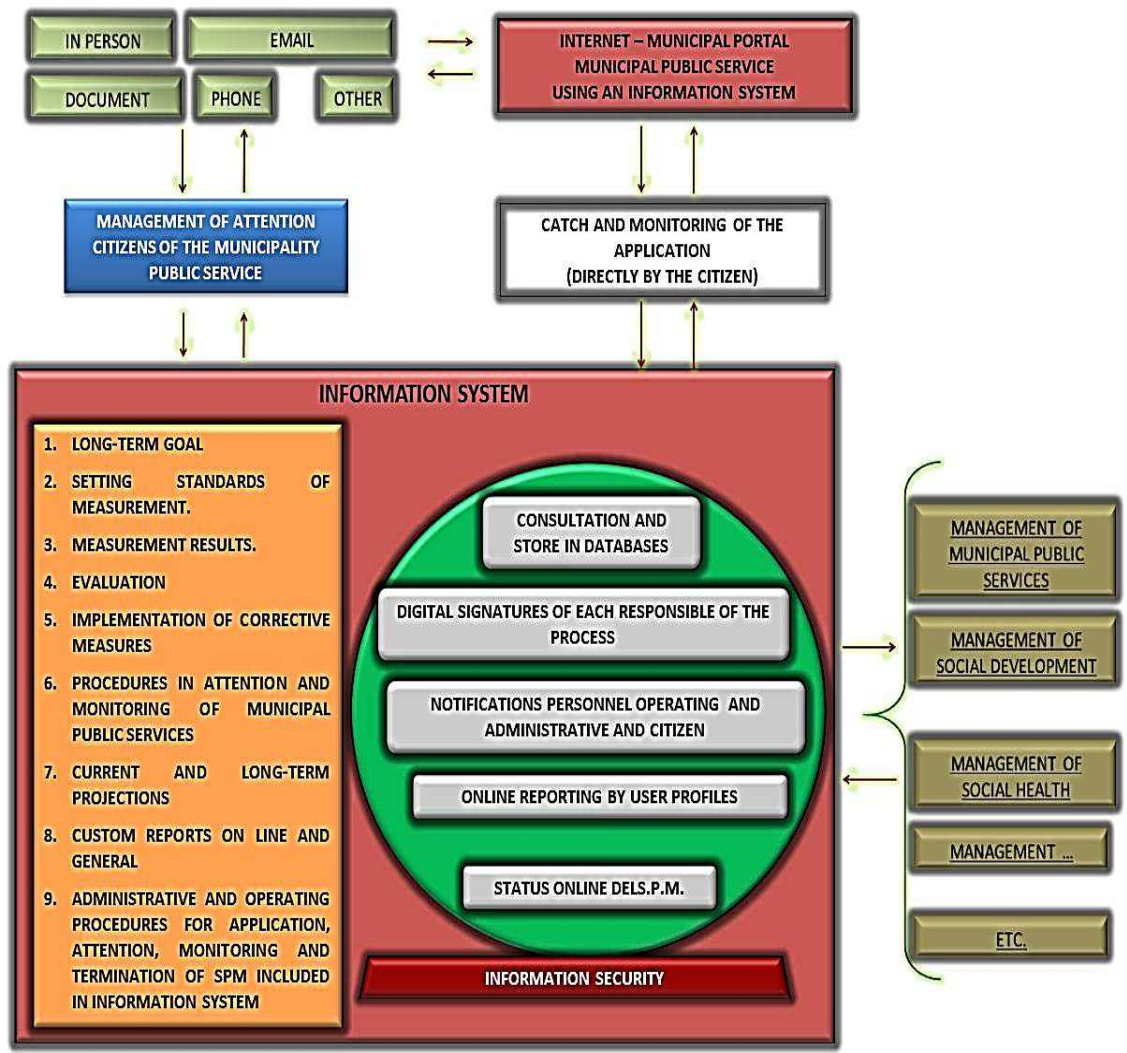

Figure 8. Information system diagram

\section{Reports}

Is proposed that the IS to begin, can generate online, general and detailed reports by direction, where it look the number of folios in waiting, they finish and to track completion. All areas must have access to reports, by corresponding profile only directions will display the total of requests regardless of the direction to which it belongs. Citizens also have access to these reports, according to folios you have requested and also according to their profile

\section{Indicator Module}

The module indicators should be presented in the IS, online and available for all directions, including the citizen. In order to analyze the progress that has in every MPS also provide ideas about continuous improvement in the management control of the MPS. In Figure 8, presented below the diagram of the information system

\section{Conclusions}

It is necessary for both government and citizens, step up action to incorporate information technologies for the benefit of all, and to provide the necessary confidence in the citizen and municipal authorities, so that through any means of application are met, the demands of municipal public service. The outlook on the use of information systems are promising, provided that a sensitization process begins learning as well as providing the technological means, increasing educational levels in each region, and disseminate by municipal authorities existence of such systems as a pathway for application, care and monitoring of any municipal public service.

This implies not only technological but also cultural evolution, since the incorporation of the information system impacts both municipal authorities and society as a whole.

With the conclusion of this investigation, the general objective was finished success, with the structuring a model for the control of municipal management through an information system, which will help streamline municipal public service, it which was the basis for the development of the research.

Moreover, the specific objectives are also met, as they managed to identify factors that prevent the incorporation of the use of information systems as a tool to help streamline the management control of municipal utilities, and it was detect the needs of citizens, in the attention of municipal public service to streamline its management.

To answer the research question was proposed structure a model for the control of management of municipal public services through an information system. Which, in the 
course of their development problems reach of technology of the population, lack of technological training of administrative and operational staff offered and attends municipal public services, lack of organization and find strategies for evaluation, Which creates opportunities for improvement in many municipal public sectors, and this proposed model contributes to these improvements.

Furthermore, in the process of field research and the use of technologies municipalities investigated, a high degree of mechanization of processes are identified, even when already have technology to replace manual processes with systematic processes to maximize resources and time in the care and monitoring of municipal public service.

Another aspect identified in this research was the lack of training for administrative and operational employees, as well as the lack of updated manuals to support flows in the care and monitoring of MPS processes which means that care is taken for common sense.

Additional to that detected a null use of information and communication technologies to support business processes or operational, technological capability unfortunately you have is still underutilized in manual processes, in which no one has control over the information handled and is susceptible to modify, delete or copy.

\section{References}

[1] Andreu, Ricart, \& Valor. (1991). En Estrategia y Sistemas de Información (pág. 13). Madrid: Mc Graw-Hill.

[2] Baca, C. (2005). Ingeniería Económica. Bogotá Colombia: Fondo Editorial Panamericano.

[3] Blank P.E, L., \& Tarquin, P.E, A. (2006). Ingeniería Económica. México: MCGraw Hill, Interamericana.

[4] Briones , G. (2002). Metodología de la investigación cuantitativa en las ciencias sociales. Bogotá, Colombia: ARFO.

[5] Castillo de la Peña. (2010). En Metodología para la elaboración del trabajo científico (págs. 228 - 229). México: Instituto Politécnico Nacional.

[6] Daltabuit Godás, E., Hernandez Audelo, L., Mallen Fullerton, G., \& Vázquez Gómez, J. (2007). La seguridad de la información. México: Noriega Editores.

[7] Dante, C. (2006). Implementacion y debugging. Chile: Zigzag.

[8] Del Rincon, D., Arnal, A., Latorre, A., \& Sans, A. (1995). Técnicas de investigación en ciencias Sociales. Madrid: Dykison.
[9] Edwars, C., Ward, J., \& Bythesway, A. (1998). Fundamentos de Sistemas de Información. Madrid: Prentice Hall.

[10] Fabrycky, W. (1997). Decisiones Económicas, análisis y proyectos. New Jersey, EUA: Editorial Prentice Hall.

[11] Fernández, Narez, \& García. (2008). En Metodología de la investigación en ciencias sociales (págs. 54 - 58). México: Grupo Editorial Patria.

[12] Finanzas públicas municipales - INEGI. (19 de 01 de 2013). catálogo general de claves para estadísticas de las finanzas públicas municipales - EFIPEM. Obtenido de www3. Inegi.org.mx

[13] García Bravo, D. (2000). Sistemas de Información en la Empresa. Madrid: Pirámide.

[14] García Córdoba, F. (2005). La investigación tecnológica. Investigar, Idear e Innovar en Ingenierías y Ciencias Sociales. México: Limusa Noriega.

[15] Garson . (2003). Las TIC's en la administración pública.

[16] Gaston, C., \& Naser, A. (2012). El desafio hacia el gobierno abierto en la hora de la igualdad. CEPAL, ONU: CEPAL, ONU.

[17] Hernández Sampieri, R., Fernández Collado, C., \& Baptista Lucio, P. (1997). Metodología de la investigación, (1ra. Ed.). Colombia: McGraw Hill.

[18] Instituto Nacional de Administración Pública - INAP. (1986). El control de la gestión municipal. México: INAP.

[19] Kaplan, R., \& Norton,, D. (2002). Cuadro de mando integral. España: Harvard College.

[20] Laudon, K., \& Laundon, J. (1996). Administración de los Sistemas de Información. México: Prentice Hall.

[21] Montaño Váquez, V. (2008). Modelo de incorporación de TIC en el proceso de innovación. México: UNAM.

[22] Penso, D. (2011). Cuerpos académicos y grupos de investigación en Análisis organizacional. Mazatlán.

[23] Rodriguez Gomez, G., Gil Flores, J., \& García Jimenez, E. (1996). Metodología de la investigación cualitativa. Málaga: ALJIBE.

[24] Sabino, C. (2002). El proceso de Investigación. Caracas: Editorial Panapo.

[25] Serra Rojas, A. (2002). Derecho administrativo. México: Porrúa.

[26] Weissbluth, M. (2008). Gestión y Políticas Públicas. Chile: Universidad de Chile. 